\title{
A Tri-state Investigation of Firearms Confiscation on Three Regional University Campuses
}

\author{
James F. Anderson ${ }^{1}$, Kellie Reinsmith-Jones ${ }^{2}$, Tazinski Lee ${ }^{3} \&$ Adam H. Langsam ${ }^{4}$ \\ ${ }^{1}$ College of Arts and Sciences, Professor of Criminal Justice, East Carolina University, Greenville, NC, USA \\ ${ }^{2}$ College of Health and Human Performances, Associate Professor of Social Work, East Carolina University, Greenville, \\ NC, USA \\ ${ }^{3}$ College of Professional and Graduate Studies, Associate Professor of Criminal Justice, Grambling State University, \\ Grambling, LA, USA \\ ${ }^{4}$ College of Liberal Arts, Professor of Sociology, Northeastern State University, Tahlequah, OK, USA \\ Correspondence: James F. Anderson, Professor, Department of Criminal Justice, East Carolina University, Greenville, \\ NC, USA.
}

Received: July 2, 2019

Accepted: July 29, 2019

Available online: August 13, 2019

doi:10.11114/ijsss.v7i5.4448

URL: https://doi.org/10.11114/ijsss.v7i5.4448

\begin{abstract}
While the use of firearms is pronounced throughout the US, there are few studies that address the availability of firearms on university campuses in states that are adjacent to each other. This study uses a five-year longitudinal design to investigate three universities that were randomly selected in the neighboring states of North Carolina, Virginia, and South Carolina to examine the extent of firearm confiscation by public safety officers. In the final analysis, we conclude that unless viable strategies that target preventing firearms used in domestic violence, alleviating access to guns, and addressing mental health illnesses among college students are created to effectively confiscate firearms on university campuses, deadly violence could become an inevitable occurrence.
\end{abstract}

Keywords: firearms, confiscation, public safety, violence, public health, mental health issues

\section{Introduction}

The use of firearms in the commission of crime is well-documented in the criminological literature since they have a pronounced presence in homicides, suicides, murder-suicides, and even accidental deaths (Siegel \& Worrall, 2018). However, Uniform Crime Reports statistics collected in 2014 revealed that the number of homicides defined as murders involving the willful killing of another had declined by $0.5 \%$ since 2013, and by $3.2 \%$ since 2010 (Federal Bureau of Investigations, 2015). In fact, these official statistics reported that as of 2014, the number of murders had fallen to 14,249 (Federal Bureau of Investigations, 2015). Similarly, public health experts reported that from 1993 to 1999, the US experienced a significant decline in firearm injuries (e.g., both fatal and non-fatal). However, from 2000 to 2012, firearms-related suicides and nonfatal firearm assaults experienced their highest levels since 1995 (Fowler et al., 2015). In fact, experts estimate that more than 32,000 people die each year, and over 67,000 are injured by firearms. Within these statistics, fatality rates are highest for self-harm related firearm injuries followed by assault-related injuries (Rhodan, 2017). Despite recent declines, both national and international criminologists argue that the proliferation and easy access to firearms in the US, along with its violent culture, makes the US more dangerous and violent than any other advanced society (Peak and Everett, 2017; Krug et al., 2002; Zimring \& Hawkins, 1997). Similarly, Hemenway (2017), reported that each day in the US, guns are linked to 90 deaths and injure more than 400 people, yet these incidents of violence are viewed as routine since the US is known for its high rates of violence.

While many Americans view gun violence and perpetrators as issues for the criminal justice system to address, healthcare experts disagree citing that acts of violence transcend the justice system and enters the public health system since firearm injuries cause many victims to seek medical treatment, medication, therapy, and adversely impact the broader society. Accordingly, Schneider (2000), reports that firearm injuries cost an estimated $\$ 48$ billion in medical fees and work loss annually that leads to a decline in national productivity. Moreover, firearm injuries are a public health issue because some victims experience premature death, illness, psychological distress including PTSD, paralysis, and other debilitating 
injuries that require assistance from healthcare providers, rather than criminal justice practitioners (Schneider, 2000). In fact, because of the sheer numbers of deaths and injuries that occur each year, the Centers for Disease Control and Prevention (CDC) (2015), argues that firearms pose a threat to public health since it estimates that each week, 645 people lose their lives to firearm violence, and 1,865 more people are transported to a hospital emergency room for treatment. Because of these reasons, experts conclude that firearm injuries are a significant public health problem that contribute to premature deaths and disabilities of many Americans, including children. While the criminological literature is replete with studies on firearm injuries in the US in general, it offers few investigations of firearm confiscation on university campuses in adjacent states. Therefore, this manuscript seeks to address a neglected area of research. More specifically, it examines firearm confiscation on three university campuses in neighboring states. As such, it is divided into four parts. Part One provides a review of the pertinent literature on firearms. Part Two presents the methodology. Part Three addresses the discussion. Part four offers policy implications. In the final analysis, we argue that unless effective strategies are used to confiscate firearms on university campuses, the end result could mean that unconfiscated weapons may be used in the commission of deadly violence.

\section{Review of the Pertinent Literature}

According to CDC reports, in 2016, an estimated 38,000 gun-related deaths occurred in the US adding 4,000 more than reported in 2015. More specifically, mortality data shows that about two-thirds were suicides and there were about 11,000 gun-related homicides in 2016, an increase from 9,600 in 2005. These numbers represent an increase in gun-related deaths that many experts believed were on a decline for nearly 15 years (Rhodan, 2017). Moreover, firearms are used in a disproportionate number of crimes in the US each year. However, epidemiologists, citing fatal firearm injury data from the National Vital Statistics System, also provide that firearms in general, but handguns in particular, are disproportionately used in fatal, as well as non-fatal injuries in the US (Fowler et al., 2015). More specifically, health officials, including many at the CDC, report that a majority of firearm deaths were suicides at a rate that exceeded 60 percent. Where race and ethnicity are concerned, reports reveal that (with the exception of suicides), young males, especially those found among certain racial and ethnic minorities are disproportionately affected by firearm injuries. Moreover, while firearm injuries had declined in the 1990s, firearm suicides and assaults have recently experienced an upswing. Additionally, nonfatal firearm assaults have also increased (Fowler et al., 2015).

Where age is concerned, Fowler and colleagues (2017) conducted research that examined the impact that firearms have on fatal and nonfatal injuries inflicted on children ages 0 to 17 . The research finds that each year, an estimated 1,300 children die, and another 5,790 sustain injuries and are treated at hospitals for gunshot wounds. The study also revealed that older male minorities are disproportionately affected. Moreover, it reported that while unintentional firearm deaths among children declined from 2002 to 2014, and firearm homicides declined from 2007 to 2014, firearm suicides decreased between 2002 and 2007, and started a significant increase from 2007 and 2014. In terms of geography, firearm-related homicides among children are higher in Southern states and in the Midwest compared with other parts of the nation. However, firearm-related suicides are equally distributed across the country with some of the highest rates found in the Western states. Surprisingly, the research revealed that firearm-related homicides among younger children typically involved a multiple victim event and involved intimate partner or family conflict while older children often died during a crime of violence. More specifically, these suicides are linked to situational and relationship problems. The research also revealed that in the majority of unintentional firearm-related deaths, the shooter was playing with the firearm (Fowler et al., 2017).

Where race and ethnicity are concerned, Riddell's (2018) research focused on nationwide differences (using death certificate data on homicides and suicides among non-Hispanic black and white men nationally from 2008 to 2016), among black and white men with experiences with fatal gun violence in the US. More specifically, this study revealed that in a nine year period from 2008 and 2016, black men were more likely to die by firearms in the commission of homicides (27 more firearm homicides per 100,000 annually or 29.12 for black men) compared with their white counterparts at 2.1 who were more likely to use firearms in suicides (5.41 for black men compared to 14.3 for white men, respectively). The rates varied widely by state and region. For example, the research showed that those states with the highest levels of black male firearm-related homicides included: Missouri, Michigan, Illinois, and Indiana. Where suicides were concerned, the states with the largest disparities included: Mississippi, Arkansas, Alabama, Texas, South Carolina, and Louisiana. Despite these statistics, the researchers reported that one surprising finding in the study was the level of variation in the rates across states. The study also relied on the 2004 data on household firearm ownership in the US and discovered a significant relationship between gun ownership with both homicide and suicide rates among white men, but a modest association with homicide and suicide rates among black men. The research concluded that blacks and whites may have different attitudes about gun ownership, however, more research needs to be conducted in this area. 
Where colleges and universities are concerned, in a report by the National Conference of State Legislatures (2016), eighteen states banned carrying concealed weapons on college and university campuses. Another twenty-four states were undecided over whether to prohibit or allow firearms on campus. Eight states allowed firearms to be carried on campus. Moreover, Patel (2018) reported on a study that tracked gunshot victims in school shootings two years after the massacre at Sandy Hook that occurred in 2012. The study revealed that an additional 239 school shootings had occurred nationwide from 2014 through 2018 in which 438 people were shot, and 138 were killed. These shootings occurred at school sporting events, in parking lots, cafeterias, hallways, and classrooms. In the end, Patel (2018), reported that between 2015 and 2016, there were on average five school shootings each month.

\section{Methodology}

This research investigation timeframe spanned four months: starting in August 2018 and ending in December 2018. It relied on a triangulated methodology that used secondary data sources and one primary data source: official campus crime data, a content analysis of existing crime statistics, and a brief telephone interview. First, campus crime statistics were requested and received from the Department of Public Safety at each of the targeted universities in the tristate area. These included: East Carolina University (ECU), Virginia Commonwealth University (VCU), and the University of South Carolina (USC), respectively. Second, official data were also downloaded from each university's webpage. Third, these data were corroborated by phoning each university's public safety crime analyst who validated the crime statistics by responding to several open-ended questions designed to measure firearm confiscations. Research experts recommend the use of mixed methods or triangulated strategies to make research investigations rigorous and robust since it uses multiple methods of data collection to address the same research question compared with relying on a single method to conduct a study. Some experts even suggest that the combination of methods can assist in verifying the accuracy of findings (see Hagan, 2014; Lanier and Briggs, 2014; Bachman and Schutt, 2008).

\subsection{Use of Official Data}

In this study, each university provided official crime data on firearm confiscations that dated from 2013 to 2018 . These data span a five-year period which makes the investigation a longitudinal measure of change regarding the number of firearms that have been confiscated on three university campuses in the same region and adjacent states. More specifically, we conducted an examination in the tri-states of North Carolina, Virginia, and South Carolina. Official data were collected and examined from East Carolina University (ECU) which has a large student population $(n=23,000)$. ECU is located in Greenville, North Carolina. Virginia Commonwealth University (VCU) also has a large student population ( $\mathrm{n}=24,212$ ). VCU is located in Richmond, Virginia, and the University of South Carolina (USC) has a similar size student population $(n=25,556)$. USC is located in Columbia, South Carolina. These southern universities were randomly selected because they have nearly the same number of undergraduate student enrollments, similar demographics, and are geographically located in states where citizens are strong Second Amendment gun rights advocates and firearm ownership is highly regarded. Moreover, southern states are known for their gun culture (Lemieux, 2014; Cohen and Nisbett, 1994). The longitudinal nature of examining five-years of data reveals trends, characteristics, and patterns of the presence of firearms on a few of the nation's university campuses for a five-year period.

\subsection{Use of Content Analysis}

As previously stated, we used a content analysis in a five-year longitudinal design to collect and analyze data at the end of each year to measure change with regard to increases or decreases in the number of weapons that university public safety officers confiscated during the time frame. More specifically, we used manifest content analysis to categorize and analyze firearm data about incidents from these three universities. Research experts such as Kraska and Neuman (2012) reported that a content analysis is a nonreactive research technique that examines information in documents. It allows researchers to document communication in materials that might otherwise go unnoticed. While performing the technique, a researcher may be required to count the number of times a word, theme, or commonality appears in any communication. Moreover, some experts refer to this method as the systematic classification of the study of mass media, such as journals, governmental documents, newspapers, books, magazines, and others (Hagan, 2014). Similarly, other scholars view content analysis as the systematic qualitative and quantitative description of communication used to discover patterns and meanings (Champion, 1993; Bachman and Schutt, 2008).

\subsection{Manifest Content Analysis and Figures}

While there are two types of content analysis: manifest and latent, we used the former to uncover items that are readily recognizable or apparent for inclusion in our analysis. However, the latter is used to uncover items with meaning that lie beneath the superficial indicators of content (Bryman, 2012). Latent content analysis requires the researcher to determine a method to decipher symbols and their meaning. It also requires an interpretation of meaning that is not immediately apparent (Bryman, 2012; Hagan, 2014). This research study used manifest content analysis. In this investigation, our hypotheses are threefold. First, we hypothesize that there is a positive relationship between laxed state gun laws 
(independent variable), and firearm confiscation (dependent variable) on college campuses. Second, we hypothesize that there is a positive relationship between a national shooting (independent variable), and firearm confiscation (dependent variable) on college campuses. Third, we hypothesize that there is a positive relationship between publicized campus gun regulations (independent variable), and firearm confiscations (dependent variable) on college campuses.

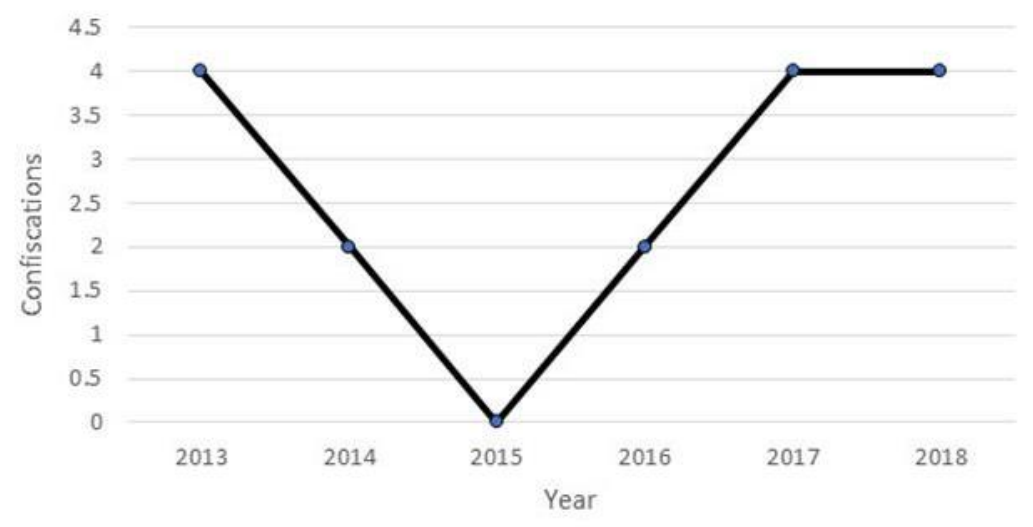

Figure 1. ECU Firearm Confiscations

Figure 1 provides the number of firearms confiscations that were reported by the Department of Public Safety at East Carolina University (ECU) in Greenville, North Carolina from 2013 to 2018. More specifically, it reveals that in 2013, there were four weapons confiscated. In 2014, the number had dropped (by 50 percent) to two weapons confiscated. In 2015, the number dropped (by 100 percent) to zero weapons confiscated. However, in 2016, there were two weapons confiscated. In 2017, ECU reported (a 200 percent increase) that four weapons were confiscated. This number has remained stable since November 2018. In its last report, the public safety department revealed that four weapons were confiscated as of October.

Figure 2 illustrates the number of firearms confiscations that were reported by the Department of Public Safety at Virginia Commonwealth University in Richmond, Virginia from 2013 to 2018. More specifically, it reveals that in 2013, there were six guns confiscated. In 2014, the number increased (by 133 percent) to eight weapons confiscated. However, in 2015, the number decreased (by 25 percent) to two weapons confiscated. In 2016, the number increased (by 250 percent) to five weapons confiscated. In 2017, VCU experienced a (250 percentage) decrease to two weapons confiscated. This number has remained stable since November 2018. In its last report, the public safety department revealed that four weapons were confiscated as of October.

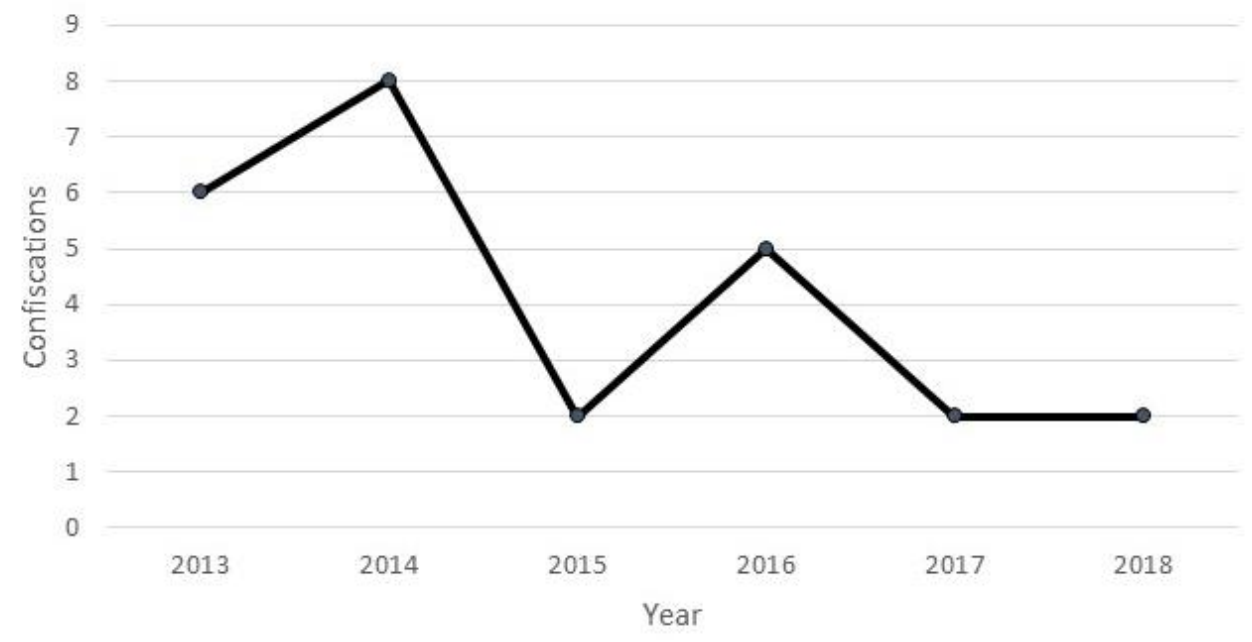

Figure 2. VCU Firearm Confiscations 


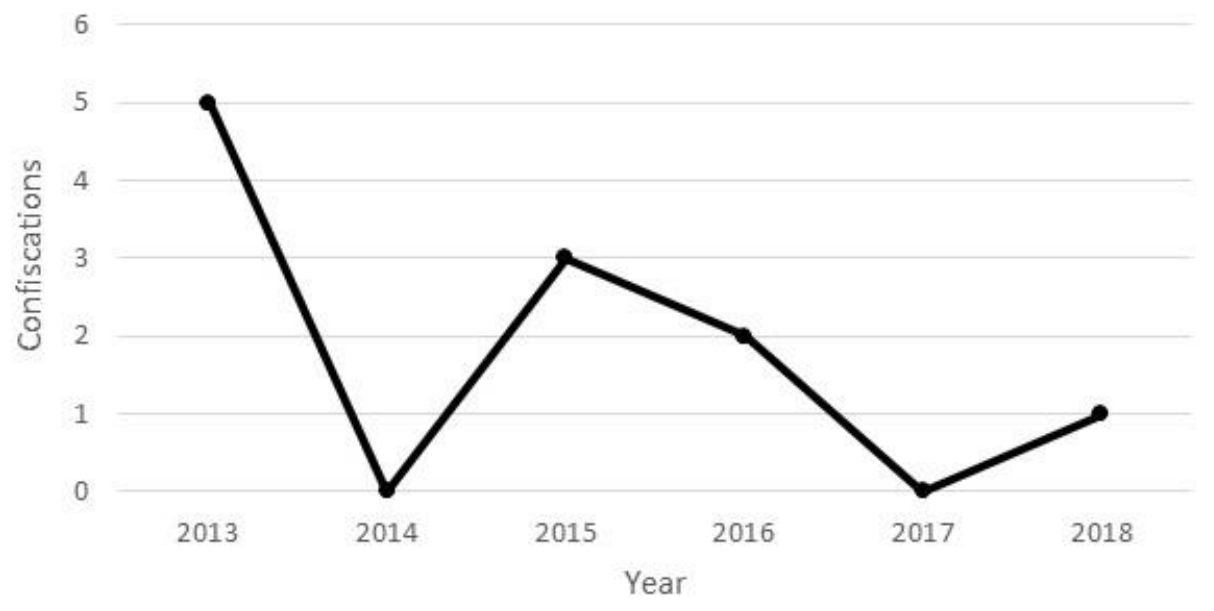

Figure 3. USC Firearm Confiscations

Figure 3 shows the number of firearm confiscations that were reported by the Department of Public Safety at the University of South Carolina in Columbia, South Carolina from 2013 to 2018. More specifically, it reveals that in 2013, there were 5 firearm confiscations. In 2014, there were zero weapons reported as being confiscated. However, in 2015, the number increased (by 60 percent) to three weapons confiscated. In 2016, the number dropped (by 40 percent) to two weapons confiscated. In 2017, there were zero weapons reported as being confiscated. However, in 2018, there was one weapon reported as being confiscated. This number has remained stable since November 2018.

\section{Discussion}

At the beginning of our investigation, we presented three hypotheses: First, we hypothesized that there is a positive relationship between laxed state gun laws $(\mathrm{X})$ and firearm confiscation $(\mathrm{Y})$ on college campuses. Second, we hypothesized that there is a positive relationship between a national shooting $(\mathrm{X})$ and firearm confiscation $(\mathrm{Y})$ on college campuses. Third, we hypothesized that there is a positive relationship between publicized campus gun regulations (X) and firearm confiscation ( $\mathrm{Y}$ ) on college campuses. To that end, we will address the first hypothesis, that there is a positive relationship between laxed state gun laws $(\mathrm{X})$ and firearm confiscation $(\mathrm{Y})$ on college campuses. To measure whether the three southern states (i.e., North Carolina, Virginia, South Carolina) in our investigation had either stringent or laxed gun control laws, we examined the criteria under which one could legally acquire a gun permit in each respective state.

\subsection{North Carolina's, Virginia's and South Carolina's Legal Requirements to Receive a Gun Permit}

We discovered that North Carolina (where ECU is located) requires an applicant to meet eleven conditions. They include the following: (a) must be a U.S. citizen, or possess naturalization papers, or have an alien registration card; (b) be at least 21 years old; (c) must establish residency in a county in NC for 30-days; (d) possess either a NC drivers' license, military ID, or valid state ID; (e) must inform the local sheriff of any involuntary mental commitments; (f) complete a firearms class; (g) not suffer from a physical or mental infirmity that prevents the safe handling of a firearm; (h) not be convicted of drunk driving within three years prior to making application; (i) must not currently be adjudicated as lacking mental capacity; and ( $\mathrm{j}$ ) not having judgement for or free on bond pending trial, appeal, or sentencing for a disqualifying criminal offense (North Carolina Gun Laws, n.d.).

When we examined Virginia's law on acquiring a gun permit (where VCU is located), we discovered that the state requires an applicant to meet twelve conditions. They include the following: (a) must be 21 years old; (b) must reside in the county where application is made; (c) demonstrate competence with a hand gun; (d) must not be convicted of two or more misdemeanors within the five year period of making application; (e) must not be indicted for being a user, or distributor of marijuana or any controlled substance; (f) not be convicted of public drunkenness within the three year period of application; $(\mathrm{g}$ ) not found by the court to be likely to use a weapon unlawfully or negligently to endanger others; (h) not convicted of any assault, assault and battery, or sexual battery; (i) must not be convicted of stalking; (j) not a person convicted as a delinquent, but whose action would have been considered a felony if committed by an adult under state law; and (k) not a person who has received mental health or substance abuse treatment in a residential setting within five years to the date of application (Virginia Gun Laws, n.d.). However, when we examined South Carolina's law to acquire a gun permit (where USC is located), we discovered that the state requires that applicants only meet six conditions that include 
the following: (a) live in SC or own property in the state; (b) be at least 21 years old; (c) must complete a firearms class; (d) cannot be convicted of a felony or violent crime; (e) must have at least 20/40 vision; and (f) cannot be deemed by a judge as unfit to carry a gun (South Carolina Gun Laws, n.d.). From these findings, we concluded that states with stringent gun laws were those that considered an applicants' mental health; past criminal record; use of illegal substances; and evidence of competence with firearms. Consequently, we concluded that North Carolina and Virginia have more stringent requirements for acquiring a gun permit. Comparatively, gun law requirements in South Carolina are laxed.

\subsection{Results from the Hypotheses}

Where gun confiscation is concerned on college campuses, we discovered mixed results since ECU and USC report greater success at gun confiscation. This finding is unexpected since South Carolina has laxed gun regulations. As such, we find modest support for the first hypothesis. In addressing the second hypothesis, that states there is a positive relationship between a national shooting $(\mathrm{X})$ and firearm confiscation $(\mathrm{Y})$ on college campuses, we examined reported incidences of national school shootings that occurred from 2013-2018. In doing so, we worked from Lemieux's (2014) premise that in the aftermath of national shootings, arguments and debates ignite about the need for stronger regulations or stricter gun control laws, especially with regards to who should be denied access. Similarly, experts, such as Metzl and MacLeish (2015), and Towers and colleagues (2015) argue that in the aftermath of mass shootings, those who are targeted as perpetrators typically include people with mental health issues, history of domestic violence, and substance abuse. Moreover, efforts are made to ban access to specific weapons (e.g., semi-automatic and clip magazine capacity). Consequently, this invariably leads some to believe that in the aftermath of shootings, national efforts are made to either repeal the Second Amendment or disarm the public. As such, it would follow that those who harbor the most concern (including college students) would begin stockpiling weapons. At the same time, Towers and colleagues (2015) argue that in the wake of school shootings, a phenomenon referred to as contagion occurs whereby it increases the likelihood that others will follow with similar behavior.

Statistics on national shootings revealed that in 2013, there were 46 incidents of gunfire that resulted in 26 deaths along with 6 suicides. There were also 35 injuries. In 2014, 67 incidents occurred that resulted in 23 deaths along with 2 suicides and 49 injuries. In 2015, there were 66 incidents of gunfire that resulted in 32 deaths, along with 6 suicides, and 55 injuries. In 2016, 57 incidents occurred that resulted in 11 deaths along with 4 suicides and 48 injuries. In 2017, there were 67 incidents of gunfire that resulted in 18 deaths along with 5 suicides and 46 injuries. In 2018, 103 incidents occurred that resulted in 60 deaths along with 7 suicides, and 88 injuries (Gunfire on School Grounds, 2019). To address the second hypothesis, that there is a positive relationship between a national shooting $(\mathrm{X})$ and firearm confiscation $(\mathrm{Y})$ on college campuses, we compared these national results with our data for the same time frame and found that at ECU, after 2013 (our benchmark), there were fewer gun confiscations reported in 2014 and 2015, but more in 2016 and 2017. However, we observed the numbers stabilizing in 2018. At VCU, like the national incidents presented earlier, there were more confiscations in 2014 and less in 2015. However, in 2016, unlike the national average, there were more in 2016, but less in 2017. We also observed a stabilizing effect that occurred in 2018. Data from USC revealed that unlike the national average, there were less gun confiscations in 2014 and more in 2015. However, the amount reflects the national average in 2017. There were fewer confiscations in 2017. We also observed that similar to the national average, USC reported more confiscations in 2018. While support was found for increases in some years, not enough support was found that spanned the entire time frame for ECU, VCU, and USC. As such, the results should be accepted with caution since the national data on school shootings provided the total numbers for 2018. Our university data did not include gun confiscations for the entire 2018 academic year because universities process these official statistics differently. Therefore, we were unable to find support for the second hypothesis, but we found modest support for contagion.

While addressing the third hypothesis, that there is a positive relationship between publicized campus gun regulations (X) and firearm confiscation $(\mathrm{Y})$ on college campuses, we examined the codes that govern firearms on ECU campus, Section 14-269.2(b) of North Carolina law prohibits any person, including a concealed handgun permit holder, from carrying a firearm, openly or concealed, on educational property or at a curricular or extracurricular activity sponsored by a school. Despite this, the law allows employees who reside on campus to carry a handgun on the employee's residential premises. It also applies to select students who are enrolled at ECU. More specifically, under North Carolina gun law, any person with a valid concealed carry handgun permit is legally allowed to possess a handgun on educational property, but certain criteria must be met. For example, the firearm must be properly stored in a locked container attached to a vehicle, such as a toolbox, or in any container in a locked vehicle. With that said, any ECU students with a valid conceal and carry permit, can legally bring a firearm on campus provided that the firearm is stored or secured in a locked vehicle in the campus parking area. Moreover, ECU informs incoming, as well as current students by publicizing its firearms policy in several areas such as: the ECU Student Code of Conduct; the Student Resident Handbook; the ECU Faculty Manual, Part XI; the N.C. Gen. Stat.IA714-269.2; and the SPA/CSS Handbook. Furthermore, ECU's Police Department provides a website directing students to ECU's policy governing firearms (Substance Abuse and Weapons Policies, 2014). 
The State of Virginia leaves firearm policy decisions to the discretion of colleges and universities in the state. Nevertheless, members of the pubic are prohibited from possessing a firearm in areas, such as academic buildings; administrative offices; student residences; dining halls; and places where sporting entertainment; and educational events are held. Moreover, in Virginia, colleges and universities are also tasked with regulating gun possession by students and employees. However, Virginia does have legal sanctions regulating firearms and other weapons on public, private, or religious property. This also extends to elementary, middle, or high schools (Code of Virginia, 2006). For example, officials at VCU inform incoming and current students by publicizing its firearms policy in the VCU Student Code of Conduct (2013). In fact, the code reveals that students are prohibited from the use, or attempted use, of a weapon and are subject to disciplinary sanctions. More specifically, the code states, in part, that only law enforcement personnel are lawfully authorized to possess or carry a weapon on VCU's campus. Moreover, it provides that weapons are prohibited on all university property including: academic offices; administrative office buildings; medical venues; clinics; laboratories; research facilities; residential halls; dining facilities; sporting events, entertainment, or educational events. From all accounts, unlike ECU which publicizes its firearm policy extensively, VCU only places its firearm policy in the Student Code of Conduct.

In South Carolina, the states' conceal and carry law affects university policy. For example, an examination of USC's website informs students that concealed carry laws are banned on campus. As such, South Carolina Code of Laws-Title 16 regarding the possession of firearms on school property states that it is unlawful to possess a firearm of any kind on any premises or property owned, operated, or controlled by a private or public school, college, university, technical college, other post-secondary institution. Moreover, Section 430 of South Carolina's Code of Laws provides that it is unlawful for any person, except state, county, or municipal law enforcement officers or personnel authorized by USC's officials, to carry a firearm while on any elementary or secondary school property; a knife, with a blade over two inches long; a blackjack; a metal pipe or pole; firearms; or any other type of weapon, device, or object which may be used to inflict bodily injury or death. In addition to state law, USC also informs incoming, as well as current student by publicizing its own firearm policy. For example, in part, its Student's Code of Conduct states that any unauthorized possession of weapons including firearms or weapons of any kind are prohibited on USC's campus. Its policy includes knives; slingshots; metal knuckles; razors; paintball guns; BB guns; and air pistols, even if permitted by law. Moreover, it provides that USC may take disciplinary action for a violation of the Code of Conduct when the offense takes place on campus, or at a university sponsored, endorsed, supported, or related event which occurs off campus. Furthermore, USC will take disciplinary actions when an offense that has occurred off campus adversely impacts the University community, its policies or procedures, or which affect the University's pursuit of its mission. With respect to publicizing its firearm policy, USC only relies on its Student Code of Conduct. Therefore, in response to the third hypothesis, we discovered that ECU does a more effective job compared with VCU and USC when publicizing its firearm policy in at least five places (e.g., Student Code of Conduct; Student Resident Handbook; ECU Faculty Manual; SPA/CSS Handbook; and ECU's Police Department website). Consequently, we believe these efforts help explain why it confiscates fewer firearms. Perhaps students enrolled at ECU are better informed about firearm prohibitions on campus or the proper method of storing them if they are legally allowed to have one on campus. We believe that the emphasis that ECU places on publicizing its firearm policy has also served as a deterrent to potential violence on campus. Hence, we find support for the third hypothesis.

\section{Policy Implications}

Criminal justicians, social workers, epidemiologists and other experts argue that gun violence is a public health issue that has reached epidemic proportions in America (Novella, 2018; Hemenway \& Richardson, 2011; Moore et al., 1994). In fact, they compare gun violence to other public health crises such as: opioids, sexually transmitted infections, auto injury and death, as well as secondary smoke death (Novella, 2018; Hemenway and Richardson, 2011). Since college campuses represent a microcosm of the larger society, students are potentially at risk of facing firearm-related injuries. Moreover, because alcohol consumption and experimental drug use is pervasive on many college campuses and is arguably viewed as part of the college culture (Kremer and Levy, 2008; Glendhill-Hoyt et al., 2002; O'Malley and Johnston, 2002; Wechsler et al., 2002), it is incumbent on university officials to maintain a safe learning environment by not allowing a toxic combination of firearms, alcohol, and drug use on their respective campuses. Nevertheless, rather than debating gun ownership rights, experts advocate firearms safety, gun violence prevention, gun policies, and legislation that is designed to lower firearm-related injuries and death (Novella, 2018). To address these concerns, experts recommend policies that address aspects of gun violence that directly affect U.S. campuses and college students. Therefore, we recommend specific policies that target the link between firearms and domestic violence; easy access to guns; and mental health as a factor in gun violence perpetrated on college campuses.

\subsection{Violence Against Women/Domestic Violence}

Between 2001 and 2013, there were 6,723 reported acts of forcible rape and fondling on college campuses across the 
nation (National Center for Education Statistics, 2016). In fact, college women between the ages of 18-24 are three times more likely than other women to be sexually victimized. Male college students, of the same age, are $78 \%$ more likely than non-college men to have experienced sexual victimization (U.S. Department of Justice, 2014). Statistics also reveal that victims reported that a weapon was used in the commission of ten percent of these crimes (U.S. Department of Justice, 2014). Research shows that during the first four years of college, $23.1 \%$ of college females are likely to be raped or sexually assaulted (Cantor et al., 2017). Moreover, one in three (or 33.3 percent) college students is estimated to be either a victim of domestic violence and/or sexual assault (U.S. Department of Education, 2016). Furthermore, intimate personal violence experts report that sexual assault is the most identifiable form of abuse within the category of domestic violence. According to the 2011 College Dating Violence and Abuse Poll, $70 \%$ of young women do not realize when they are abused by a partner (Knowledge Networks, 2011). Of 340 women in this study, $43 \%$ reported having experienced "physical, sexual, technology, verbal, or controlling abuse," with $52 \%$ reporting that they have a friend who has experienced the same (p.11). For 2016, ECU reported 2 cases of domestic violence, 17 events of dating violence, and 16 acts of stalking. VCU reported 29, 17, and 20 respectively; and USC reported 3, 5, and 8 respectively (U.S. Department of Education, 2016). Overall, for that same year, ECU reported 3 weapons law violations, VCU reported 60, and USC reported 3 (U.S. Department of Education, 2016). This is important because the presence of a firearm in a domestic violence situation typically increases the likelihood that a homicide will occur to intimate partners as well as to corollary victims (Smith, Fowler, \& Niolon, 2014; Campbell et al., 2003). Therefore, some firearms experts believe that the implementation of a background check on every gun sold is essential and may assist preventing females from becoming the victims of homicide by an estimated 38\% (Federal Bureau of Investigations, 2010).

\subsection{Easy Access to Guns}

Public health officials report that acquiring access to guns (the second deadliest weapon next to a motor vehicle), is relatively easy in America (Moore et al., 1994; Shane et al., 2018). In 2016, there were 40,327 auto-related deaths and 38,658 firearm-related deaths (U.S. Department of Health and Social Services, 2018; National Safety Council, 2018). Additionally, an estimated 85,000 gun-related injuries occur annually (American Public Health Association, 2018). Firearms are readily available at sporting goods stores and sporting goods departments within major retailers, pawn shops, specialty shops, online, and gun shows. In 2017, the Bureau of Alcohol, Tobacco, Firearms, and Explosives reported that $5,137,771$ weapons were legally imported into the U.S. and 11,497,441 were legally manufactured in the U.S. The exact numbers of illegally manufactured guns (e.g., guns made from 3-D printers, imports, or sale of guns) are unknown (U.S. Department of Justice, 2017). In 2017, 12 states permitted conceal carry of weapons on campuses, 22 states allowed colleges and universities to decide their own conceal carry policy which included Virginia, and 16 states did not permit conceal carry, including North and South Carolina (Winn, 2017). While public safety officers can enforce HB937 on college campuses and other university- owned property, it cannot enforce HB937 on student housing property not owned by the university which includes off-campus student housing. While many students may be responsible gun owners, it is difficult to ignore the rise in mental illness being reported on campuses nationally and the role that mental illness can play in gun violence, including mass shootings and suicides.

\subsection{Mental Health on Campus as a Factor in Gun Violence}

According to the Gun Control Act, any person who is either: (a) an unlawful user of or addicted to controlled substances; (b) deemed mentally unfit or has been institutionalized; (c) has a military dishonorable discharge; (d) has a restraining order filed against him/her or has been convicted of a domestic violence misdemeanor is not allowed to own a firearm (Greenfeld, 2005). However, this does not prevent anyone from acquiring illegal firearms nor protects students who live on a university campus or attend classes on campus. In fact, the most dangerous shootings that occur on college campuses are random shootings and student suicides. What is unknown to the lay public is that there has been a rise in the number of students seeking mental health services on college and university campuses. In fact, the National Survey of College Counseling Centers reported an increase from 44\% in 2013 to 52\% in 2014 of students experiencing "severe psychological problems" (Gallagher, 2015) with similar findings by the American College Health Association (ACHA). The ACHA survey results revealed that $52.7 \%$ of the student respondents reported feeling "hopeless," and 39.1\% reported depression so severe that it impaired their ability to function properly (American Psychological Association, 2019). Furthermore, the Association for University and College Counseling Center Directors reported that the most prevalent disorders that students sought help with during the academic year 2017-2018, according to 621 U.S. campus counseling centers, were "anxiety (48.2\%); stress (39.1\%); depression (34.5\%); suicidal ideation (25.2\%); specific relationship concerns $(22.9 \%)$; family concerns $(21.2 \%)$; [relationship problem]-interpersonal functioning problems (18.8\%); sleep problems (15.8\%); and loneliness/social isolation (15.5\%)" (Tate, 2017p. 11). Of these students, $25.5 \%$ were prescribed psychotropic medication, and $16.2 \%$ had treatment histories involving serious suicide attempts and/or psychiatric hospitalizations (Tate, 2017). Of these student centers, there was an average 7 day wait period for a first appointment, and $32 \%$ of centers reported the need for a waitlist on which students waited 17 days before being seen. Of 432 centers, there 
were 6,822 crisis appointments; 276 students were sent to a hospital for psychological reasons, and 243 were admitted (Tate, 2017). It is important to report that murder on college campuses occurs less than suicide between 2001 and 2014,28 murders on college and university campuses were reported (U.S. Department of Education, 2016). However, this does not account for murders of students, by students, that occurred on off-campus student housing, or at other off-campus locations that students frequent.

The U.S. Department of Health and Human Services (2018) reported that suicide was the second cause of death among persons ages 10-34. Among those of typical college age between 15-24, there were 5,723 suicides committed disproportionately by males. Firearms were the most common method for male suicide at $56.6 \%$ and the second most common method for females, at $32.1 \%$. What is equally disturbing is that the highest percent of persons with suicidal thoughts, as well as the highest percent of persons attempting suicide are disproportionately between the ages 18-25. Of all suicide attempts with a gun, $75 \%$ to $91 \%$ have been successful (Miller, Azrael \& Hemenway, 2004; Razaeian \& Sharifirad, 2012).

Firearm confiscations on college campuses may appear to be an inconsequential way to decrease firearm violence and death. However, we believe that less access to guns could result in less gun violence, especially acts of domestic violence, sexual assaults, and untimely deaths. In states with the highest rates of gun ownership in 2008, there were 16,577 suicide deaths by firearms as compared with 4,257 in states with the lowest rates of gun ownership (Miller \& Hemenway, 2008). In the wake of mass shootings, the International Association of Campus Law Enforcement Administrators (2018), has called for re-evaluation of existing gun ownership and acquisition laws and policies. They favor expanding the Comprehensive School Safety Initiative to colleges and universities. They recommend raising the age for purchase of rifles to age 21. Furthermore, they advocate expanding campus mental health services. A similar position has been announced by the National Association of Student Personnel Administration (NASPA). Moreover, Hazekorn (2011) reported that the Student Affairs Administrators in Higher Education also opposes a law that expands legal possession of firearms on campuses other than by trained law enforcement officers. The NASPA represents 50,000 student affairs administrators and more than 2,000 campuses. College campuses across the nation are taking steps to create healthier spaces for students to live and learn. They are sincere in their efforts to prevent campus violence. Not every college student owns a gun, but it is likely that most students know a student who either owns or has access to a firearm. Gun confiscation on campus is only one way to help make college a safer more productive experience. We believe that since ECU is having success with gun confiscation efforts, perhaps other colleges and universities can do the same if they use similar strategies. We advocate removing firearms from college and university settings since confiscated firearms cannot be used in the commission of crime and violence. We strongly recommend that more research needs to be conducted in this neglected area of criminal justice study.

\section{References}

American Public Health Association. (2018). Gun violence. Retrieved from https://www.apha.org/topics-and-issues/gun-violence

American Psychological Association. (2019). Campus mental health. Retrieved from https://www.apa.org/advocacy/higher-education/mental-health/index.aspx.

Bachman, R., \& Schutt, R. K. (2008). Fundamentals of research in criminology and Criminal Justice. Thousand Oaks, CA: Sage.

Bryman, A. (2012). Social Research Methods (4 ${ }^{\text {th }}$ ed.). New York, NY: Oxford University Press.

Campbell, J. C., Webster, D., Koziol-McLain, J., Block, C., Campbell, D., Curry, M. A., \& Laughon, K. (2003). Risk factors for femicide in abusive relationships: Results from a multisite case control study. American Journal of Public Health, 93(7), 1089-1097. https://doi.org/10.2105/AJPH.93.7.1089

Cantor, D., Fisher, B., Chibnall, S., Townsend, R., Lee, H., Bruce, C., \& Thomas, G. (2017). Report on the AAU campus climate survey on sexual assault and sexual misconduct. Rockville, MD: Westat, An Employee-Owned Research Corporation.

Centers for Disease Control and Prevention. (2015). National Center for Injury Prevention and Control. Web-based Injury Statistics Query and Reporting System. Available from URL: www.cdc.gov/ncipc/wisquars

Champion, D. J. (1993). Research Methods for Criminal Justice and Criminology. Englewood Cliffs, NJ: Regents/Prentice-Hall.

Code of Virginia (2006). Retrieved from https://law.lis.virginia.gov/vacode/18.2-308.1/

Cohen, D., \& Nisbett, R. E. (1994). Self-protection and the culture of honor: Explaining southern homicide. Personality and Social Psychology Bulletin, 20(5), 551-567. https://doi.org/10.1177/0146167294205012 
Federal Bureau of Investigation (2010). Crime in the United States, 2014. Washington, DC: U.S. Department of Justice. Federal Bureau of Investigation (2015). Crime in the United States, 2014. Washington, DC: U.S. Department of Justice.

Flower, K. A., Dahlberg, L. L., Haileyesus, T., \& Arnest, J. L. (2015). Firearms injuries in the United States. Preventive Medicine, 79,5-14. https://doi.org/10.1016/j.ypmed.2015.06.002

Flower, K. A., Dahlberg, L. L., Haileyesus, T., Gutierrez, C., \& Bacon, S. (2017). Childhood firearms injuries in the United States, Pediatrics, 140(1), 1-13. https://doi.org/10.1542/peds.2016-3486

Gallagher, R. P. (2015). National survey of college counseling centers 2014. Project report. The International Association of Counseling Services (IACS).

Glendhill-Hoyt, J., Lee, H., Strote, J., \& Wechsler, H. (2002). Increased use of marijuana and other illicit drugs at US colleges in the 1990s: Results of three national surveys. Addiction, 95(11), 1655-1667. https://doi.org/10.1046/j.1360-0443.2000.951116556.x

Greenfeld, L. A. (2005). Survey of state procedures related to firearm sales Midyear 2004. U.S. Department of Justice, Office of Justice Programs, Bureau of Justice Statistics. Washington, DC.

Gunfire on School Grounds in the United States (2019). Retrieved from https://www http://everytownresearch.org/gunfire-in-school

Hagan, F. E. (2014). Research Methods in Criminal Justice and Criminology ( $9^{\text {th }}$ ed.). Upper Saddle River, NJ: Pearson.

Hazekorn, E. (2011). Ranking and reshaping of higher education: The battle for world class excellence. Dublin Institute of Technology, Centre for Social and Educational Research.

Hemenway, D. (2017). Private guns, public health. Ann Arbor, MI: University of Michigan Press. https://doi.org/10.3998/mpub.9725179

Hemenway, D., \& Richardson, E. G. (2011). Homicide, suicide and unintentional firearm fatality: comparing the United States with other high-income countries. J Trauma, 70(1), 238-243. https://doi.org/10.1097/TA.0b013e3181dbaddf

International Association of Campus Law enforcement Administrators (2018). Position state on reducing gun violence. Retrieved from https://www. iaclea.org

Knowledge Networks. (2011). 2011 College dating violence and abuse poll. Retrieved from http://www.loveisrespect.org/pdf/College_Dating_And_Abuse_Final_Study.pdf

Kremer, M., \& Levy, D. (2008). Peer Effects and Alcohol Use among College Students. Journal of Economic Perspectives, 22(3), 189-206.

Kraska, P. B., \& Neuman, W. L. (2012). Criminal Justice and Criminology Research Methods (2 ${ }^{\text {nd }}$ ed.). Upper Saddle River, NJ: Pearson.

Krug, E. G., Dahlberg, L. L., Mercy, J. A., Zwi, A. B., \& Lozano, R. (2002). World Report on Violence and Health (pp 321-323). World Health Organization: Geneva.

Lanier, M., \& Briggs, L. T. (2014). Research methods in criminal justice and criminology: A mixed methods approach. New York, NY: Oxford University Press.

Lemieux, F. (2014). Effect of gun culture and firearm laws on gun violence and mass shootings in the United States: A multi-level quantitative analysis. International Journal of Criminal Justice Sciences, 9(1), 74-93.

Metzl, J. M., \& MacLeish, K. T. (2015). Mental illness, mass shootings, and the politics of American firearms. (2015). American Journal of Public Health, 105(2), 240-249.

Miller, M., Azrael, D., \& Hemenway, D. (2004). The epidemiology of case fatality rates for suicide in the northeast. Annals of Emergency Medicine, 43(6), 723-730.

Miller, M., \& Heneway, D. (2008). Guns and suicides in the United States. New England Journal of Medicine, 359(10), 989-991.

Moore, M. H., Prothrow-Stith, D., Guyer, B., \& Spivak, H. (1994). Violence and intentional injuries: criminal justice and public health perspectives on an urgent national problem. In AJ Reiss, Jr and JA Roth (Eds.), Understanding and Preventing Violence, Volume 4: Consequences and Control, 167-216. Washington, DC: National Academy Press.

National Center for Education Statistics (2016). Indicator 21: Criminal incidents at postsecondary institutions. Retrieved from https.www.nces.ed.gov 
National Conference of State Legislatures. (2016). Guns on campus overview. Retrieved from http://www.ncsl.org/research/education/guns-on-campus-overview.aspx

National Safety Council. (2018). Injury facts: Deaths by demographics. Retrieved from https://injuryfacts.nsc.org/all-injuries/deaths-by-demographics/top-10-preventable-injuries

North Carolina Gun Laws: The Latest Guide. (n.d.). Retrieved from https://www.gunstocarry.com/gun-laws-state/northcarolina-gun-laws

Novella, S. (2018). Gun violence as a public health issue: Gun violence is a serious public health issue in America but is not getting the research it deserves. Retrieved from http://sciencebased medicine.org/gun-violence-as-a-public-health-issue

O’Malley, P. M., \& Johnston, L. D. (2002). Epidemiology of alcohol and other drug use among American college students. Journal of Studies on Alcohol, Supplements, (s14), 23-39. https://doi.org/10.15288/jsas.2002.s14.23

Patel, J. K. (2018). The New York Times. Retrieved from (http://www.nytimes.com

Peak, K. J., \& Everett, P. M. (2017). Introduction to criminal justice: Practice and process ( $2^{\text {nd }}$ ed.). Thousand Oaks, CA: Sage Publications.

Razaeian, M., \& Sharifirad, G. (2012). Case fatality rates of different suicide methods within Ilam province of Iran. Journal of Education and Health Promotion, 1(44), 15-17. https://doi.org/10.4103/2277-9531.104814

Rhodan, M. (2017). Gun-related deaths in America keep going up. Retrieved from https://www.usatoday.com/videos/news/2017/11/06/gun-related-deaths

Riddle, C. A. (2018). Comparison of rates of firearms and nonfirearm homicide and suicide in black and white non-Hispanic men by state. Annals of Internal Medicine, 168(10), 712-721. https://doi.org/10.7326/M17-2976

Schneider, M. J. (2000). Introduction to public health. Gaithersburg, MD. Aspen Publishers.

Shane, P. D., Petrosky, E., Lyons, B. H., Blair, J. M., Ertl, A. M., Sheats, K. J., \& Betz, C. J. (2018). Surveillance for Violent Deaths-National Violent Death Reporting System, 27 States, 2015. Morbidity and Mortality Weekly Report, 67(11), 1-32. https://doi.org/10.15585/mmwr.ss6711a1

Siegel, L. K., \& Worrall, J. L. (2018). Introduction to criminal justice $\left(16^{\text {th }}\right.$ ed.). Belmont, CA: Cengage.

Smith, S. G., Fowler, K.A., \& Niolon, P. H. (2014). Intimate Partner Homicide and Corollary Victims in 16 States: National Violent Death Reporting System, 2003-2009. American Journal of Public Health, 104(3), 461-466.

South Carolina Gun Laws: The Latest Guide. (n.d.). Retrieve from https://www.gunstocarry.com/gun-laws-state/southcarolina-gun-laws

Substance Abuse \& Weapons Policies, 2014). Retrieved from http://www.ecu.edu

Tate, E. (2017). Anxiety on the rise. Retrieved from https//www.insidehighered.com

Towers, S., Gomez-Lievano, A., Khan, M., Mubeyi, A., \& Castillo-Chavez, C. (2015). Contagion in mass killings and school shootings. PlusOne, 10(7),1-12. https://doi.org/10.1371/journal.pone.0117259

U.S. Department of Education. (2016). Table 329.10: On-campus crimes, arrests, and referrals for disciplinary action at degree-granting postsecondary institutions, by location of incident, control and level of institution, and type of incident: 2001 through 2014. National Center for Education Statistics. Retrieved from https://nces.ed.gov/programs/digest/d16/tables/dt16_329.10.asp

U.S. Department of Education. (2016). The campus safety and security data analysis cutting tool, calculated from 2014 data files. Washington, DC: U.S. Department of Education. Retrieved from https://ope.ed.gov/campussafety

U.S. Department of Health and Social Services. (2018). Table I-3. Number of deaths, death rates, and age-adjusted death rates for injury by firearms, by race and Hispanic origin and sex: United States, 1999-2016. National Vital Statistics Reports, 67(5), 1-80.

U.S. Department of Health and Human Services, National Institute of Mental Health. (2018). Suicide. Retrieved from https://www.nimh.nih.gov/health/statistics/suicide.shtml

U.S. Department of Justice. (2017). Firearms commerce in the United States: Annual Statistical Update. Bureau of Alcohol, Tobacco, Firearms and Explosives.

U.S. Department of Justice. (2014). Rape and Sexual Victimization Among College-Aged Females, 1995-2013, NCJ 248471. Office of Justice Programs, Bureau of Justice Statistics. Retrieved from https://bjs.gov/content/pub/pdf/rsavcaf9513.pdf 
VCU Student Code of Conduct. (2013). Retrieved from (https://conduct.students.vcu.edu/student-code-of-conduct).

Virginia Gun Laws: The Latest Guide. (n.d.). Retrieved from https://www.gunstocarry.com/gun-laws-state/virginia-gun-laws

Wechsler, H., Lee, J., Kuo, M., \& Lee, H. (2002). College binge drinking in the 1990s: A continuing problem. Journal of American College Health, 48(5), 199-210. https://doi.org/10.1080/07448480009599305

Winn, Z. (2017). A list of states that allow concealed guns on campus. Campus Safety. Retrieved from https://www.campussafetymagazine.com/university/list-of-states-that-allow-concealed-carry-guns-on-campus

Zimring, F., \& Hawkins, G. (1997). Crime is not the problem: Lethal violence in America. New York, NY: Oxford University Press.

\section{Copyrights}

Copyright for this article is retained by the author(s), with first publication rights granted to the journal.

This is an open-access article distributed under the terms and conditions of the Creative Commons Attribution license which permits unrestricted use, distribution, and reproduction in any medium, provided the original work is properly cited. 